\title{
Evaluation of the potentialities of the essential oil of Ocimum gratissimum Linn. toward environmental and industrial perspectives through microbial exploitation
}

\author{
Pranab Giri* \\ Department of Botany, Dum Dum Motijheel College, 1, Motijheel Avenue, Kolkata, West Bengal, India
}

Received: 22.05.2017

Accepted: 10.06.2017

Published: 15.06.2017

*Address for correspondence: Pranab Giri, Department of Botany, Dum Dum Motijheel College, 1, Motijheel Avenue, Kolkata - 700074 ,

West Bengal, India.

Phone: +91-9830110563,

E-mail: giri_pranab@yahoo.in

\begin{abstract}
Nature has its own machinery to regulate spontaneous interaction between biotic and abiotic factors of its own to provide back up for self-stability and sustainability. The plant-microbe interaction is a biotic interaction the resultant of which has an immense role to resolve different environmental issues. It also has some fruitful effect for welfare of human beings. The present article deals with at what extent the biotic interaction between the essential oil from Ocimum gratissimum and microbial resources from the natural environment could be exploited in respect of environmental as well as industrial perspectives.
\end{abstract}

KEY WORDS: Antimicrobial property, biotransformation, biovanillin, essential oil, eugenol, growth incentive property, Ocimum gratissimum

\section{INTRODUCTION}

The genus Ocimum is an aromatic Labiate plant. In the agroclimatic condition of West Bengal, it is represented by 6 species (Banerjee, 1996). The bioactive principle of different species is the essential oil which is mainly obtained from leaves. The essential oil contains diverse arrays of biochemical compounds which have immense medicinal properties and the compounds are also exploited industrially for manufacture of different compounds needed in our daily life. Eugenol is a common compound available in the essential oil of different species of this genus (Joshi, 2013). It is of great economic value since it is used as a precursor compound for industrial production of vanillin (Rana et al., 2013). Natural vanillin (4-hydroxy-3-methoxy benzaldehyde) is extracted from the pods of Vanilla planifolia (Orchidaceae). Most of the world's vanillin is synthesized from petrochemicals or wood pulp lignins (Figure 1).

Vanillin holds tremendous industrial applications in food, pharmaceuticals, beverages, perfumes, and as nutraceuticals. It has high economic value as it is used as a flavoring agent. It has a global market of 180 million dollars (Hansen et al., 2009). The growth inhibitory property of vanillin to pathogenic and spoilage microorganisms has been demonstrated in vitro (Rupasinghe et al., 2006). The extracted vanillin from this natural resource represents $<1 \%$ of annual market demand and has a market price 300 times higher than synthetic vanillin (Kaur and Chakraborty, 2013). Not only that, the industrial demand for natural vanillin exceeds the amount of vanillin extracted from the said plant. This has led to the investigation of alternative routes for the production of this flavor enriching compound. Different molecular and biotechnological protocols have been adopted from time to time using diverse type of substrates for production of vanillin (Kaur and Chakraborty, 2013). Certain microorganisms including bacteria and fungi have the ability to transform the substrate into vanillin by a multistep process exploiting their metabolic enzymes in the fermentation medium (Converti et al., 2010). A single pervaporation step has been adopted for sustainable recovery of pure natural vanillin from fermentation medium (Brazinha et al., 2011). Using isoeugenol as a substrate, natural vanillin production has been demonstrated using a novel strain of Pseudomonas chlororaphis (Kasana et al., 2007). The role of oxidative enzyme vanillin dehydrogenase has also investigated in 
Amycolatopsis sp. strain ATXX 39116 (Fleige et al., 2013). The homologous activity of the enzyme is revealed in the reagent $\mathrm{H}_{2} \mathrm{O}_{2}$-vanadate-pyrazine-2-carboxylic acid (Gusevskaya et al., 2012) (Figure 2).

The waste residue of rice bran oil could be used as a substrate for production of vanillin by Aspergillus niger and Pycnoporus cinnabarinus (Zheng et al., 2007). Solid state fermentation approach has also effectively designed to produce vanillin by growing Phanerochaete chrysosporium on green coconut agro-industrial husk (dos Santos Barbosa et al., 2008). Application of in silico design is the modern approach on fission yeast (Schizosaccharomyces pombae) for improved vanillin production (Brochado et al., 2010). The biovanillin production from natural substrate will, therefore, be a cost-effective and alternative approach since it might have potentialities to fulfil the demand for natural vanillin. In this regard, natural eugenol could be an effective substrate for production of vanillin through fermentation technique.

Natural eugenol is obtained mainly from Eugenea caryophyllata and Cinnomomum zeylanicum. However, the eugenol yield could be achieved at the satisfactory level only when plants matured sufficiently which practically requires prolonged time. Being enrich source of eugenol very scanty report is available whether the essential oil

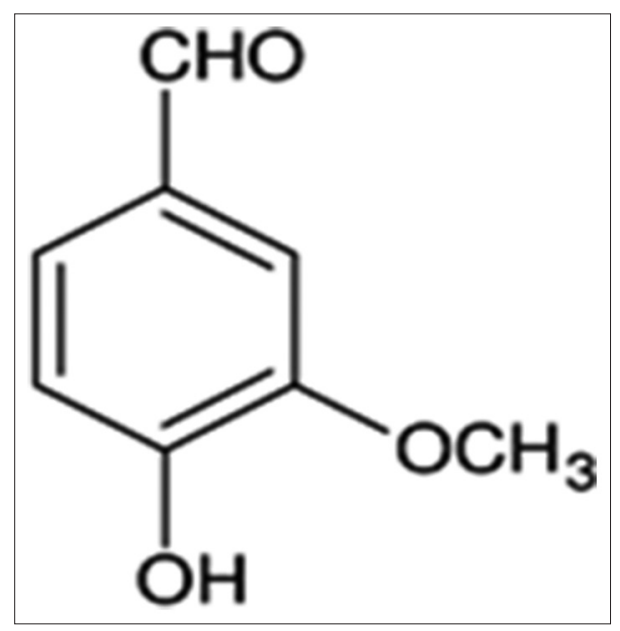

Figure 1: Chemical structure of vanillin

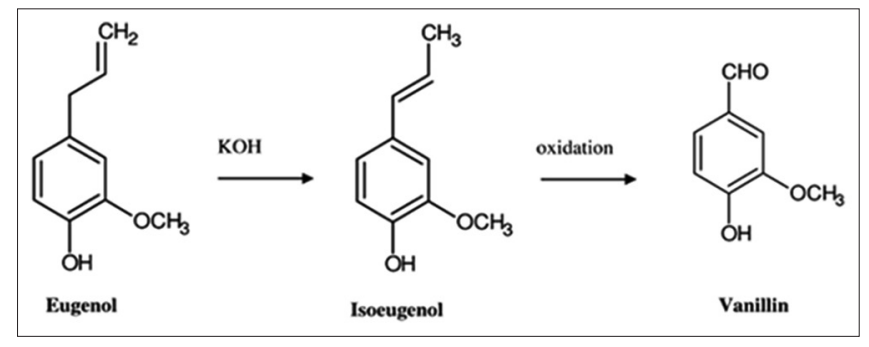

Figure 2: Production of vanillin through eugenol of different species of Ocimum could be exploited as an alternative substrate material for industrial production of vanillin. Despite growth inhibitory nature of the essential oil of different species of the plant whether eugenol present in the oil sample could be exploited for industrial vanillin production using microbes from natural environment has not investigated so far. Therefore, our investigation is aimed to determine the following aspects:

i. Determination of most efficient eugenol yielding species of Ocimum among the available species under the same genus growing in the agroclimatic regions of West Bengal.

ii. Isolation of eugenol resistant microorganisms from putrescent environment to evaluate their potentiality to uptake eugenol in their metabolic stream with the possibility for the biotransformation of the same into aroma compound vanillin. The expected field of implication of such study is to demonstrate the possibility of augmentation of the crude leaves of the efficient eugenol producing species to abate the stink of obnoxious odor coming out from the putrescent environment.

iii. Qualitative estimation of vanillin in the reaction mixture where the resistant microorganism is growing using eugenol of the essential oil as a substrate.

\section{MATERIALS AND METHODS}

\section{Preparation of Leaf Extract}

$10 \mathrm{~g}$ of dry thoroughly, washed leaves were surface sterilized with $90 \%$ alcohol. The leaves were ground in a mortar pestle using $10 \mathrm{ml}$ petroleum ether as solvent. The macerates were kept at room temperature for solvent evaporation. In the remaining residue, $10 \mathrm{ml}$ of distilled water was added. Macerates were squeezed through double-layered muslin cloth and filtered through filter paper. The aliquots were then centrifuged at 10,000 rpm for $20 \mathrm{~min}$. The supernatant was filtered through Whatman No. 1 filter paper and then, sterilized by passing through $0.2 \mu$ disposable filters to add into the reaction mixture.

\section{Extraction of Oil Sample}

Oil sample from fresh leaves was extracted following hydrodistillation method using Clevenger apparatus.

\section{Quantitative Estimation of Eugenol in the Essential Oil of Different Species of Ocimum}

The percentage $(\mathrm{w} / \mathrm{w})$ of eugenol was measured after detecting the existence of the same in the test sample by comparing the retention time (RT) of gas chromatogram 
(GC) peaks of the test sample and that of the standard authentic ones.

Before GC analysis, a stock concentration was prepared both for the authentic sample and test sample. For example, the stock concentration of authentic sample ' $X$ ' was prepared as $\mathrm{M}$ ppm, and the concentration of test sample was prepared as $\mathrm{N} \mathrm{ppm}$. Both stock concentrations was prepared by dissolving them into HPLC, $n$-hexane. If the injected volume for test sample and authentic sample being 1 microliter, then the (\%) of ' $\mathrm{X}$ ' available in the test sample could be calculated by the following formula:

The concentration $(\%)$ of $\mathrm{X}$ in the test sample= $\frac{\mathrm{M} \times \mathrm{A}_{2} \times 100}{\mathrm{~A}_{1} \times \mathrm{N}}$

Where $\mathrm{M}=$ Standard stock concentration (ppm),

$\mathrm{A}_{1}=$ Area of the standard authentic sample (obtained from chromatogram),

$\mathrm{A}_{2}=$ Area of the test sample (obtained from chromatogram), $\mathrm{N}=$ Stock concentration of the test sample (ppm).

\section{Evaluation of Growth Incentive Properties of Leaf Extract and Essential Oil}

To determine the growth incentive property of the essential oil for bacteria, a mixture of $10 \mathrm{ml}$ nutrient broth, $0.2 \mathrm{ml}$ inoculum, and $1 \mathrm{~mm}$ sterilized $\mathrm{DDH}_{2} \mathrm{O}$ was used as control set. In experimental set, instead of water $1 \mathrm{~mm}$ filter sterilized extract and oil were separately added. The reaction mixture was incubated at $37^{\circ} \mathrm{C}$ for $24 \mathrm{~h}$. The optical density was then measured at $540 \mathrm{~nm}$. Fungal growth was measured using $10 \mathrm{ml}$ Czapek dox liquid medium $+0.1 \mathrm{ml}$ spore suspension (inoculum) $+1 \mathrm{ml}$ $\mathrm{DDH}_{2} \mathrm{O}$ as a control set and $10 \mathrm{ml}$ Czapek dox liquid medium $+0.1 \mathrm{ml}$ spore suspension (inoculum) $+1 \mathrm{ml}$ filter sterilized extract and oil (separately) as experimental set. Increase in the dry weight of the mycelia from the control was expressed as percentage of growth acceleration.

\section{GC Analysis of Oil Sample}

GC analysis of oil samples of different species of Ocimum was made with the help of a CE-8000 top model chromatogram using liquid nitrogen as a carrier gas. The oven temperature of the chromatogram was raised from $60^{\circ} \mathrm{C}-220^{\circ} \mathrm{C}$ at the rate of $5^{\circ} \mathrm{C} / \mathrm{min}$. The holding time of the final temperature in the oven was $10 \mathrm{~min}$. The injector and detector temperature was $220^{\circ} \mathrm{C}$ for each. The column used for GC analysis was DB- 5 mass spectrometry type of capillary column of $30 \mathrm{mt}$ length. The film thickness and internal diameter of the column was $25 \mu \mathrm{m}$. The concentrated essential oil samples were diluted properly up to a particular concentration using n-hexane as a solvent, and one microliter of diluted samples were injected into the chromatogram for analysis. The authentic samples were also diluted similarly, and the same volume was injected into the column. The peaks produced by authentic samples were compared to the peaks obtained from the test samples with respect to their RT to the identification as well as quantification of the constituents present in the oil samples.

\section{RESULTS AND DISCUSSION}

The estimation of the eugenol content in the essential oil of 6 different species of Ocimum (O. sanctum, Ocimum gratissimum, Ocimum kilimandscharicum, Ocimum basilicum, Ocimum adscendens, and Ocimum americanum) growing in West Bengal reveals that the compound is present in all the species with significant variation in its quantity (Figure 3). The relative area percentage of the compound as represented in the data given with the Figure of GC analysis specifies that in O. gratissimum its possession is highest in comparison to other constituents (Figures 4 and 5). This observation corroborates with the quantity of eugenol content (47.25\%) in the essential oil of this species calculated on the basis of formulation designed in our experiment. Since the herbage begetting of this species is very high so essential oil obtained from this species could be considered as an ideal source of eugenol. To verify whether the essential oil of this species could be effectively used as an ideal eugenol enriched substrate for microbial growth, irrespective of its antimicrobial nature, 10 bacterial, and four (4) fungal isolates were allowed to grow both in presence of leaf extract and essential oil. The result presented in the Table 1 shows that out of ten bacterial isolates only three (SDM101, MID103, KLR103) can resist the inhibitory activity of essential oil and exhibit growth promotion. Such growth incentive property is also observed in favor of the same three isolates where

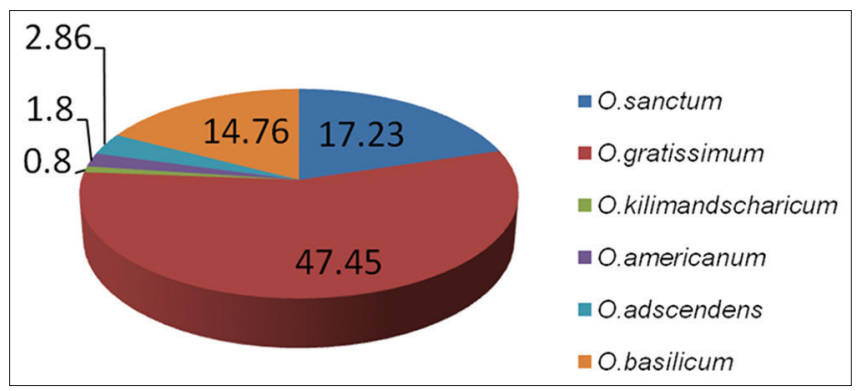

Figure 3: Percentage of eugenol content in the oil of different species of Ocimum. The eugenol content in the oil in Ocimum gratissimum is significantly higher than other species as estimated through gas chromatogram analysis of oil sample 


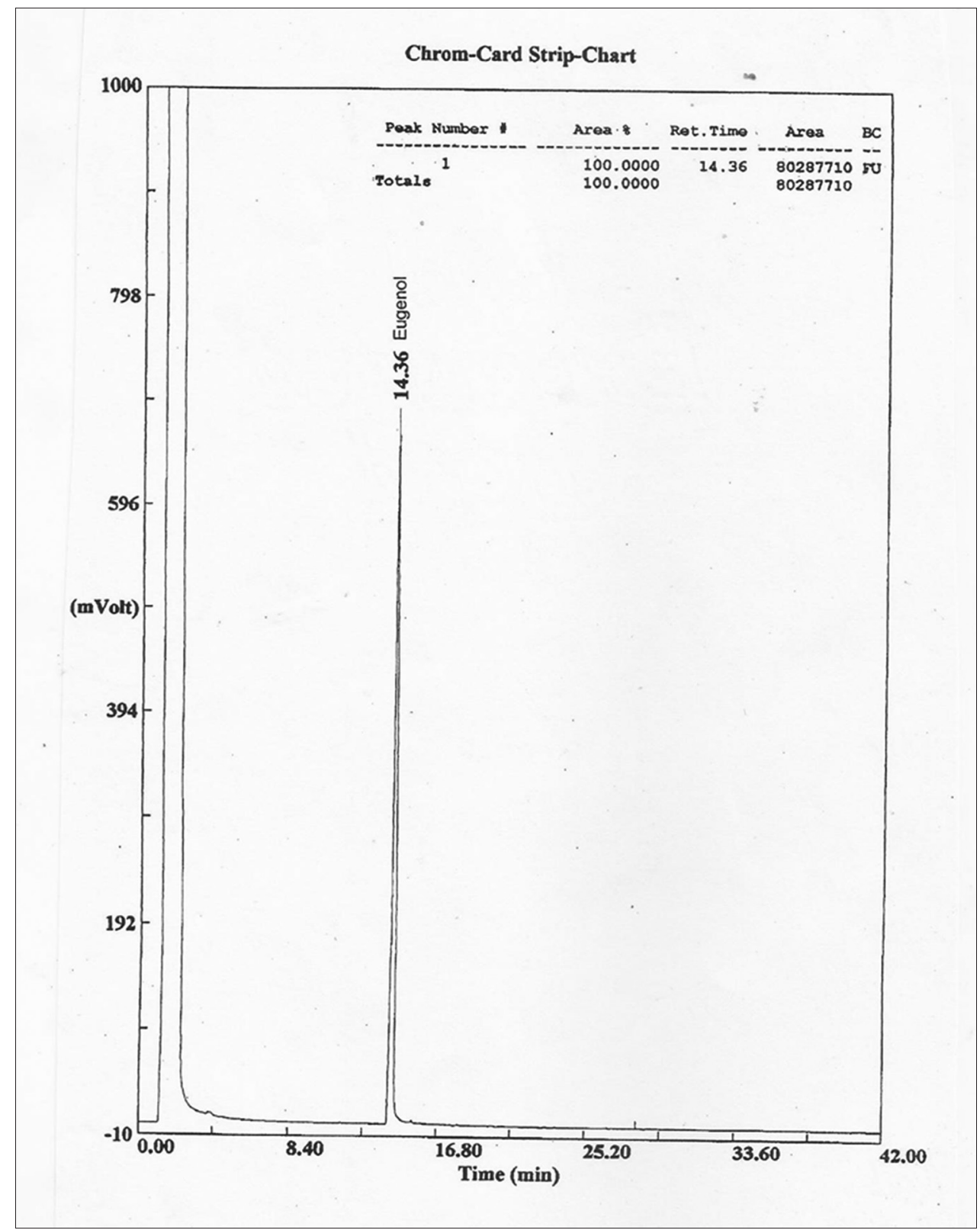

Figure 4: Gas chromatogram of the authentic sample of eugenol

Table 1: Effect of leaf extract and volatile oil on the growth of different bacterial isolates

\begin{tabular}{lcccc}
\hline Isolates number & \multicolumn{3}{c}{ Optical density of reaction mixture at $540 \mathrm{~nm}$ after incubation } \\
\cline { 2 - 5 } & Control & Reaction mixture with leaf extract & Reaction mixture with volatile oil & Reaction mixture with eugenol \\
\hline SDM101 & $0.59 \pm 0.02^{\mathrm{b}}$ & $0.72 \pm 0.1^{\mathrm{ab}}$ & $0.74 \pm 0.002^{\mathrm{a}}$ & $0.72 \pm 0.001^{\mathrm{ab}}$ \\
KJV102 & $0.31 \pm 0.01^{\mathrm{a}}$ & $0.21 \pm 0.03^{\mathrm{bcd}}$ & $0.24 \pm 0.001^{\mathrm{bc}}$ & $0.25 \pm 0.002^{\mathrm{b}}$ \\
MID103 & $0.34 \pm 0.05^{\mathrm{b}}$ & $0.78 \pm 0.11^{\mathrm{a}}$ & $0.78 \pm 0.005^{\mathrm{ab}}$ & $0.78 \pm 0.004^{\mathrm{abc}}$ \\
RMV104 & $0.36 \pm 0.002^{\mathrm{a}}$ & $0.28 \pm 0.05^{\mathrm{bcd}}$ & $0.25 \pm 0.01^{\mathrm{b}}$ & $0.27 \pm 0.02^{\mathrm{bc}}$ \\
MDR211 & $0.46 \pm 0.011^{\mathrm{a}}$ & $0.36 \pm 0.06^{\mathrm{b}}$ & $0.35 \pm 0.04^{\mathrm{bc}}$ & $0.36 \pm 0.014^{\mathrm{b}}$ \\
KLR103 & $0.42 \pm 0.02^{\mathrm{b}}$ & $0.75 \pm 0.04^{\mathrm{ab}}$ & $0.76 \pm 0.03^{\mathrm{a}}$ & $0.72 \pm 0.005^{\mathrm{abc}}$ \\
DID001 & $0.64 \pm 0.04^{\mathrm{a}}$ & $0.51 \pm 0.02^{\mathrm{b}}$ & $0.48 \pm 0.002^{\mathrm{bc}}$ & $0.49 \pm 0.006^{\mathrm{bcd}}$ \\
PAN002 & $0.52 \pm 0.03^{\mathrm{a}}$ & $0.33 \pm 0.01^{\mathrm{b}}$ & $0.32 \pm 0.05^{\mathrm{bc}}$ & $0.33 \pm 0.004^{\mathrm{b}}$ \\
SDM102 & $0.44 \pm 0.11^{\mathrm{a}}$ & $0.39 \pm 0.05^{\mathrm{bc}}$ & $0.39 \pm 0.004^{\mathrm{bc}}$ & $0.38 \pm 0.011^{\mathrm{b}}$ \\
SDM103 & $0.68 \pm 0.06^{\mathrm{a}}$ & $0.44 \pm 0.012^{\mathrm{bc}}$ & $0.43 \pm 0.001^{\mathrm{bcd}}$ & $0.46 \pm 0.012^{\mathrm{b}}$ \\
\hline
\end{tabular}

Values are mean $\pm S D$; Different superscripts represent mean comparison by Duncan's test at $5 \%$ level of significance. Similar alphabet show homogeneous mean. SD: Standard deviation 


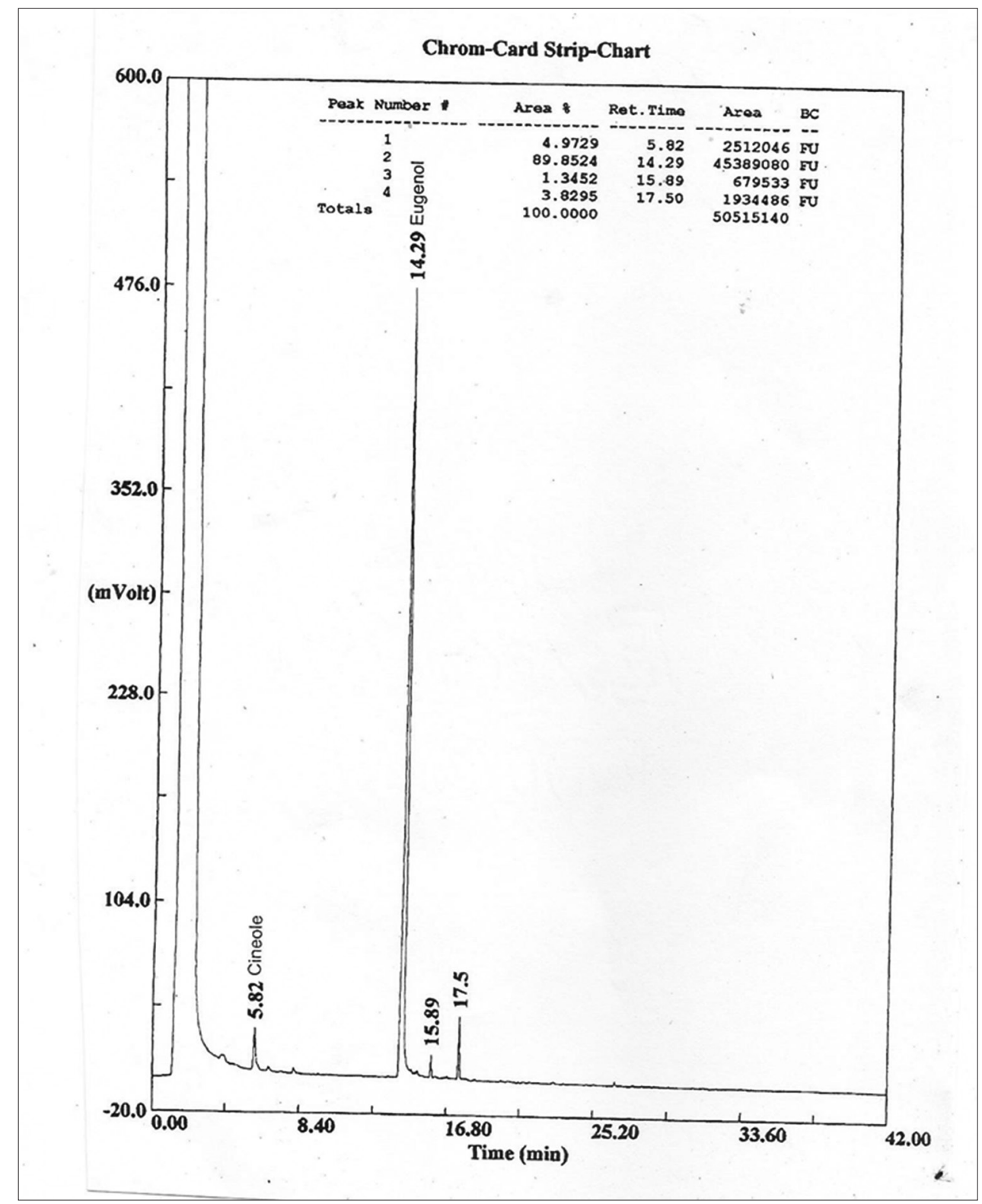

Figure 5: Gas chromatogram of the essential oil of Ocimum gratissimum

reaction mixture is supplemented with eugenol instead of essential oil. Hence, eugenol in the essential oil could not exert its antimicrobial property that might be due to its integration into the metabolic stream of the bacterial isolates. Such integration is favorable for acceleration of the growth of the isolates instead of the retardation. Similar observation was also noticed in case of fungal isolates where mycelial dry weight is decreased except one when they were allowed to grow in medium supplemented with leaf extract as well as essential oil. The medium containing authentic sample of eugenol also shows growth promotion in case of only one fungal isolate out of four (Figure 6). Other possibilities might be predicted from this observation by corroborating the study which reveals the free radical scavenging and antioxidative potential of eugenol existing in the essential oil of O. gratissimum (Mahapatra and Roy, 2014).

Whatever might be the cause of growth incentive activity of the essential oil of this species, it is true that eugenol is pervaded in the metabolic stream of both fungal and bacterial isolates which could be evidenced by the qualitative existence of the vanillin - a de novo compound in the reaction mixture presented in the Figure 8. Thus, microbial conversion of natural eugenol to natural vanillin could be possible in certain microbial strain though not all. Many reports are available in this regard where eugenol resistivity is due to its bioconversion into industrially important compound vanillin. Amplification of 16s RNA gene reveals that one such eugenol resistant strain is 


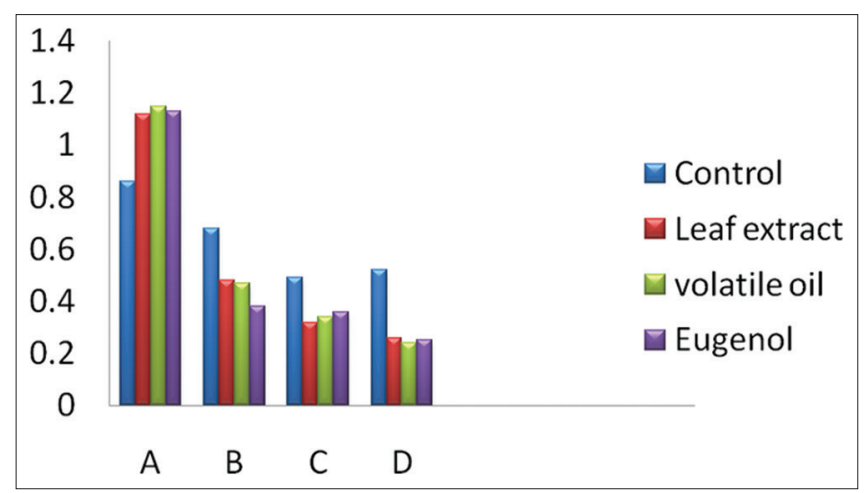

Figure 6: Effect of leaf extract and essential oil of Ocimum gratissimum on the growth of four fungal different isolates

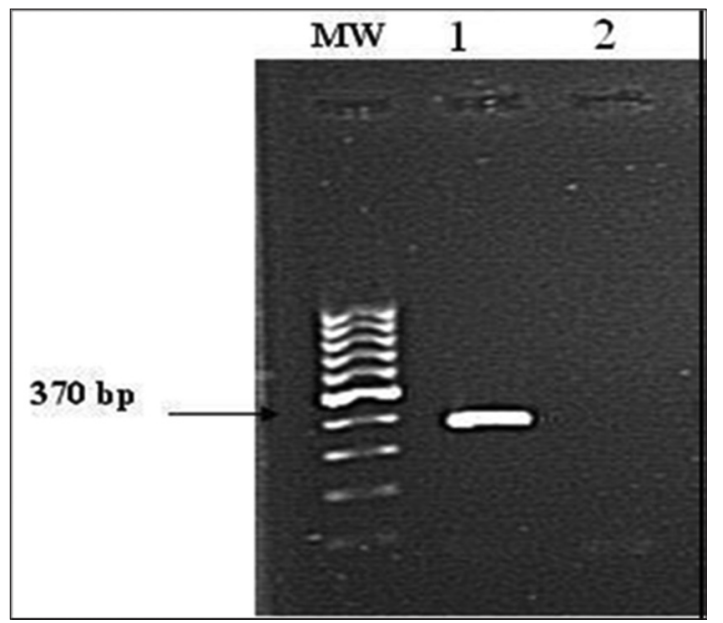

Figure 7: Amplification of 16rRNA gene of isolated strain of Pseudomonas auregenosa

Source: By courtesy Ashengroph et al., Indian Journal of Pharmaceutical Research 2011:10(4): 749-757

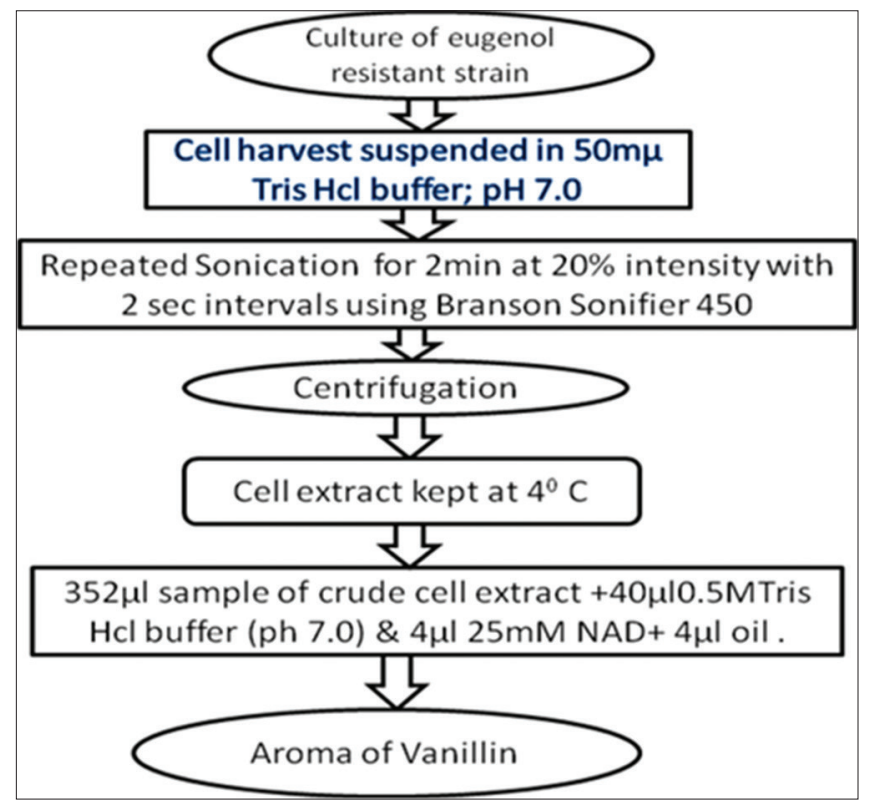

Figure 8: Protocol for qualitative estimation of vanillin in reaction mixture
Pseudomonas auregenosa which has immense potentiality for production of biovanilin (Figure 7) (Ashengroph et al., 2011).

Thus, it could be concluded that natural environment has many potent microorganisms capable of transforming natural substrate into products of commercial importance. In our present investigation, the production of vanillin through microbial interaction with the natural substrate might have some positive perspective on environment since the microbes have been collected here from putrefied environment such as vat or storage bin where natural fermentation process continuously generate obnoxious odor. In such sites, crude leaves of O. gratissimum could be applied where natural vanillin production through biotic interaction might lead to rapture the stink of unpleasant odor (Figure 8).

Still, quantitative analysis of biotransforming ability of the microorganisms is to be investigated in detail with the view to determine the feasibility of the volatile oil of $O$. gratissimum as an ideal substrate for industrial production of vanillin. Moreover, molecular techniques are to be applied for accurate identification of such isolates to generate a database of eugenol resistant microbial wealth which would be advantageous for future screening of most efficient isolates for vanillin production in a commercial scale.

\section{REFERENCES}

Ashengroph M, Nahvi I, Zarkesh-Esfahani H, Momenbeik F. Use of growing cells of Pseudomonas aeruginosa for synthesis of the natural vanillin via conversion of isoeugenol. Iran J Pharm Res 2011;10:749-57.

Banerjee S. Taxonomic Revision of Some Genera of the Tribe Ocimoidae (Lamiaceae) of India. Ph.D. Thesis, University of Kalyani, Kalyani, Nadia; 1996.

Brazinha C, Barbosa DS, Crespo JG. Sustainable recovery of pure natural vanillin from fermentation media in a single pervaporation step. Green Chem 2011;13:2197-203.

Brochado AR, Matos C, Møller BL, Hansen J, Mortensen UH, Patil KR. Improved vanillin production in baker's yeast through in silico design. Microb Cell Fact 2010;9:84.

Converti A, Aliakbarian B, Domínguez JM, Bustos Vázquez G, Perego P. Microbial production of biovanillin. Braz J Microbiol 2010;41:519-30.

dos Santos Barbosa E, Perrone D, do Amaral Vendramini AL, Leite SG. Vanillin production by Phanerochaete chrysosporium grown on green coconut agro-industrial husk in solid state fermentation. Bioresources 2008;3:1042-50.

Fleige C, Hansen G, Kroll J, Steinbüchel A. Investigation of the 
Amycolatopsis sp. Strain ATCC 39116 vanillin dehydrogenase and its impact on the biotechnical production of vanillin. Appl Environ Microbiol 2013;79:81-90.

Gusevskaya EV, Menini L, Parreira LA, Mesquita RA, KozlovYN, Shul'pin GB. Oxidation of isoeugenol to vanillin by the " $\mathrm{H}$ 2 O 2-vanadate-pyrazine-2-carboxylic acid" reagent. J Mol Catal A Chem 2012;363:140-7.

Hansen EH, Møller BL, Kock GR, Bünner CM, Kristensen C, Jensen OR, et al. De novo biosynthesis of vanillin in fission yeast (Schizosaccharomyces pombe) and baker's yeast (Saccharomyces cerevisiae). Appl Environ Microbiol 2009;75:2765-74.

Joshi RK. Chemical composition, In vitro antimicrobial and antioxidant activities of the essential oils of Ocimum Gratissimum, O. Sanctum and their major constituents. Indian J Pharm Sci 2013;75:457-62.

Kasana RC, Sharma UK, Sharma N, Sinha AK. Isolation and identification of a novel strain of Pseudomonas chlororaphis capable of transforming isoeugenol to vanillin. Curr
Microbiol 2007;54:457-61.

Kaur B, Chakraborty D. Biotechnological and molecular approaches for vanillin production: A review. Appl Biochem Biotechnol 2013;169:1353-72.

Mahapatra SK, Roy S. Phytopharmacological approach of free radical scavenging and anti-oxidative potential of eugenol and Ocimum gratissimum Linn. Asian Pac J Trop Med 2014;7:S391-7.

Rana R, Mathur A, Jain CK, Sharma SK, Mathur G. Microbial production of vanillin. Int $\mathrm{J}$ Biotechnol Bioeng Res 2013;4:227-34.

Rupasinghe HV, Boulter-Bitzer J, Ahn T, Odumeru JA. Vanillin inhibits pathogenic and spoilage microorganisms in vitro and aerobic microbial growth in fresh-cut apples. Food Res Int 2006;39:575-80.

Zheng L, Zheng P, Sun Z, Bai Y, Wang J, Guo X. Production of vanillin from waste residue of rice bran oil by Aspergillus niger and Pycnoporus cinnabarinus. Bioresour Technol 2007;98:1115-9. 